\title{
Outcomes of cancer survivorship education and training for primary care providers: a systematic review
}

\author{
Raymond J. Chan 1,2,3 (1) - Oluwaseyifunmi Andi Agbejule ${ }^{1,2}$. Patsy M. Yates ${ }^{1,2,3} \cdot$ Jon Emery $^{4} \cdot$ Michael Jefford $^{4,5}$. \\ Bogda Koczwara $^{6}$ - Nicolas H. Hart ${ }^{1,2,7,8} \cdot$ Megan Crichton $^{1,2} \cdot$ Larissa Nekhlyudov $^{9}$
}

Received: 22 February 2021 / Accepted: 5 March 2021 / Published online: 24 March 2021

(C) The Author(s), under exclusive licence to Springer Science+Business Media, LLC, part of Springer Nature 2021

\begin{abstract}
Purpose To identify published literature regarding cancer survivorship education programs for primary care providers (PCPs) and assess their outcomes.

Methods PubMed, Embase, and CINAHL databases were searched between January 2005 and September 2020. The Quality of Cancer Survivorship Care Framework and Kirkpatrick's 4-level evaluation model were used to summarize program content and outcomes, respectively. Data extraction and critical appraisal were conducted by two authors.

Results Twenty-one studies were included, describing self-directed online courses $(n=4)$, presentations ( $n=2)$, workshops and training sessions $(n=6)$, placement programs $(n=3)$, a live webinar, a fellowship program, a referral program, a survivorship conference, a dual in-person workshop and webinar, and an in-person seminar and online webinar series. Eight studies described the use of a learner framework or theory to guide program development. All 21 programs were generally beneficial to PCP learners (e.g., increased confidence, knowledge, behavior change); however, methodological bias suggests caution in accepting claims. Three studies reported positive outcomes at the patient level (i.e., satisfaction with care) and organizational level (i.e., increased screening referrals, changes to institution practice standards).

Conclusions A range of cancer survivorship PCP education programs exist. Evidence for clinical effectiveness was rarely reported. Future educational programs should be tailored to PCPs, utilize an evidence-based survivorship framework, and evaluate patient- and system-level outcomes.

Implications for Cancer Survivors PCPs have an important role in addressing the diverse health care needs of cancer survivors. Improving the content, approach, and evaluation of PCP-focused cancer survivorship education programs could have a positive impact on health outcomes among cancer survivors.
\end{abstract}

Keywords Cancer $\cdot$ Education $\cdot$ Evaluation $\cdot$ Primary care $\cdot$ Survivorship $\cdot$ Theory

Raymond J. Chan and Oluwaseyifunmi Andi Agbejule are co-first authors.

Raymond J. Chan

raymond.chan@qut.edu.au

1 Cancer and Palliative Care Outcomes Centre, Queensland University of Technology, Brisbane, QLD, Australia

2 School of Nursing, Faculty of Health, Queensland University of Technology, Brisbane, QLD, Australia

3 Division of Cancer Services, Princess Alexandra Hospital, Brisbane, QLD, Australia

4 Centre for Cancer Research and Department of General Practice, Faculty of Medicine, Dentistry and Health Sciences, University of Melbourne, Melbourne, VIC, Australia
5 Australian Cancer Survivorship Centre, Peter MacCallum Cancer Centre, Melbourne, VIC, Australia

6 Flinders Center for Innovation in Cancer and Flinders Medical Centre, Flinders University, Adelaide, SA, Australia

7 School of Medical and Health Sciences, Edith Cowan University, Perth, WA, Australia

8 Institute for Health Research, University of Notre Dame Australia, Perth, WA, Australia

9 Department of Medicine, Brigham and Women's Hospital, Harvard Medical School, Boston, MA, USA 


\section{Background}

Advances in early detection, diagnostics, and treatment have resulted in an increase in cancer survivors living with and beyond cancer. As of 2018, there were approximately 43.8 million cancer survivors worldwide [1], a number that is projected to grow substantially over the next 15 years [2]. In addition to the risk of subsequent primary cancer and cancer recurrence, many cancer survivors will experience late and long-term side effects as a result of their cancer and treatment, along with new and pre-existing comorbidities [3]. As global cancer survival rates continue to improve, the need to address the range of physical, psychological, and psychosocial needs of survivors through continuous follow-up support is paramount. The challenges of addressing the long-term health care needs of an increasing number of cancer survivors, along with the projected shortage and pressure on the specialist oncology workforce [4-6], have led to a call for primary care providers (PCPs) to move beyond the traditional focus on cancer prevention and early detection [7], to the provision of posttreatment follow-up survivorship care [7-12].

The benefits of integrating primary care into cancer survivorship follow-up care are well established, resulting in enhanced continuity and satisfaction of care [13, 14], as well as improved or similar physical and psychosocial well-being of cancer survivors [15-18]. Despite the clear importance of the primary care team in survivorship care, limited data on the engagement of PCPs in survivorship care exist. Moreover, several studies have demonstrated a need for quality cancer survivorship education within the primary care workforce, with PCPs often reporting a lack of appropriate knowledge [19-21], training [22, 23], and confidence [19, 20, 24-26] in providing adequate cancer survivorship support. Additionally, there is a critical need for cancer survivorship curricula, relevant to the primary care provider role, to be formally integrated into primary care residency training (e.g., internal/general medicine) as deficiencies in existing programs and syllabuses (e.g., self-reported unpreparedness for practice in cancer survivorship, low levels of survivorship training or education) have been widely reported in literature [27-30]. Despite several calls to action [7, 9], a recent cross-sectional study [27] identified that among 249 family medicine programs in the USA, only $9.2 \%$ reported having a cancer survivorship curriculum or program.

Primary care providers are well placed to deliver quality patient-centered survivorship follow-up care; and thus, competency in cancer survivorship is essential. While studies have investigated perspectives of PCPs in providing survivorship care and have highlighted the importance of addressing training deficiencies, a systematic evaluation of existing survivorship education programs targeted towards the primary care workforce has not been completed. This is necessary to determine the impact and outcomes of education program components as well as to establish more specific, actionable recommendations. Accordingly, this systematic review was conducted to identify and evaluate existing PCP cancer survivorship programs in published literature and answer the following questions: (1) What are the behavioral/learning theories, pedagogy, and/or frameworks used in PCP survivorship education programs? (2) What are the effects of PCP survivorship education programs on outcomes for PCPs (e.g., knowledge, attitude, behaviors) and for cancer survivors (e.g., health and clinical outcomes, self-efficacy)?

\section{Methods}

This systematic review was prepared and reported according to the Preferred Reporting Items for Systematic Reviews and Meta-Analyses (PRISMA) guidelines [31] (Supplementary 1). The review was registered with PROSPERO (No. CRD42021223836), where a protocol was submitted. The current review has been conducted in accordance with that protocol.

The Quality of Cancer Survivorship Care Framework [32] was used to define survivorship care and guide article inclusion. This framework is similar to the ASCO Core Curriculum for Cancer Survivorship but provides more detailed information to guide the classification and categorization of survivorship content [33]. Education programs were considered "survivorship care programs" if they described or contained at least one of the following core domains: (1) cancer and cancer treatment (prevention and surveillance for recurrences and new cancers; surveillance and management of physical effects; surveillance and management of psychosocial effects; surveillance and management of psychosocial effects); (2) general health care (surveillance and management of chronic medical conditions; health promotion and disease prevention); and (3) contextual domains (clinical structure; communication and decision-making; care coordination; patient/caregiver experience). A description of these domains is displayed in Supplementary 2. Further, in accordance with this framework, palliative and end-of-life care were not included under this scope of survivorship care.

For this review, an educational program was defined using the United Nations Educational, Scientific and Cultural Organization's (UNESCO) International Standard of Classification of Education [34]. In this classification an education program is defined as:

A coherent set or sequence of educational activities designed and organized to achieve pre-determined learning objectives or accomplish a specific set of educational tasks over a sustained period. Within an education programme, educational activities may also be grouped into sub-components variously described in national 
contexts as 'courses', 'modules', 'units' and/or 'subjects'. A programme may have major components not normally characterized as courses, units or modules for example, play-based activities, periods of work experience, research projects and the preparation of dissertations.

This includes, but is not limited to workshops, curricula, seminars, webinars, courses, training sessions, modules, coaching sessions, role-play sessions, fellowships, placement programs, self-based learning, and lectures.

\section{Selection criteria}

Study titles were considered eligible for inclusion if the study or program evaluated met the following criteria: (1) describe a "survivorship care program" as per the above definition, (2) describe and evaluate an education program, (3) report outcomes of the evaluation, (4) explicitly specify PCPs as the intended participants of the program or include PCPs as a learner type, and (5) be written in English. Only studies published after 2005 were included as this was the year the Institute of Medicine (IOM) published the seminal From Cancer Patient to Cancer Survivor: Lost in Transition report [8]. Further, only articles or abstracts with published evaluated outcomes were eligible for inclusion. To ensure review comprehensiveness, original research articles (any methods), conference abstracts, and other grey literature with evaluated outcomes (e.g., online modules, institutional training programs, e-learning programs) were included. No restrictions were placed on setting or modality of survivorship education programs (i.e., web-based, face-to-face, telephone).

\section{Search strategy}

Three databases (PubMed, Embase, and CINAHL) were searched between January 2005 and September 2020 using the search strategy listed in Supplementary File 3. Reference lists of all full text articles were checked for potentially relevant programs and studies. Google Scholar was also searched for additional studies. Titles and abstracts of articles retrieved from the search strategy were independently screened by two authors (RC, OAA). The same two authors then assessed the eligibility of relevant full-text articles for inclusion in the review. Disagreements were resolved through consensus among the two authors, with a third author (LN) as arbiter where required.

\section{Data extraction}

Data extraction was conducted by one author (OAA) and checked for accuracy by a second author (MC and RC). Key information extracted included author, publication year, study type, research methods, program/resource objectives, curriculum content, pedagogy, learning theories used, course participants, and survivorship components. Survivorship components were included if they were explicitly listed in the study or were attained via external information (e.g., ancillary documents, internet resources, education program website, study author confirmation, review team knowledge). Study outcomes were categorized and synthesized using Barr's adaptation (the addition of two sub-domains) of Kirkpatrick's 4-level model of evaluation [35] displayed in Supplementary File 4. This model specifies four levels of training evaluation: reaction, views on learning experience; learning, the modification of learner attitudes and acquisition of knowledge and skills; behavior change, the transfer of learning to the workplace; and results, changes in organizational practice or benefits to patients. Survivorship program content was independently categorized by two authors (OAA and RC) using the Quality of Cancer Survivorship Care Framework, with inclusion of special populations considerations (e.g., adolescents and young adults, geriatric populations). Disagreements regarding data extraction were discussed and resolved between the two authors.

\section{Quality assessment and analysis}

Quality assessment of pre-test, post-test studies was undertaken using the NIH "quality assessment tool for before-after (pre-post) studies with no control group" [36]. Post-test only studies were also appraised using this tool, with items pertaining to pre-test, post-test differences recorded as "not applicable." Mixed-methods studies were appraised using the mixed-methods appraisal tool [37]. Disagreements regarding methodological quality of the studies were discussed and resolved between two authors (OAA and MC). If consensus was not reached, a third author (RC) acted as arbiter. Review findings were presented in narrative form due to study heterogeneity.

\section{Results}

Database searches resulted in 2555 potentially eligible records. Of these, 24 articles (seven abstracts and 17 full text studies) representing 21 studies and evaluating 21 unique survivorship education programs [38-58] met the inclusion criteria and were included in the review (see PRISMA flow chart: Fig. 1).

\section{Characteristics of included studies}

Studies characteristics are detailed in Table 1. All 21 studies utilized single-group designs with no comparators. Thirteen studies [38-40, 42, 43, 45, 46, 48, 51, 55-58] used a pre-test, 
Fig. 1 PRISMA 2020 flow diagram for systematic reviews

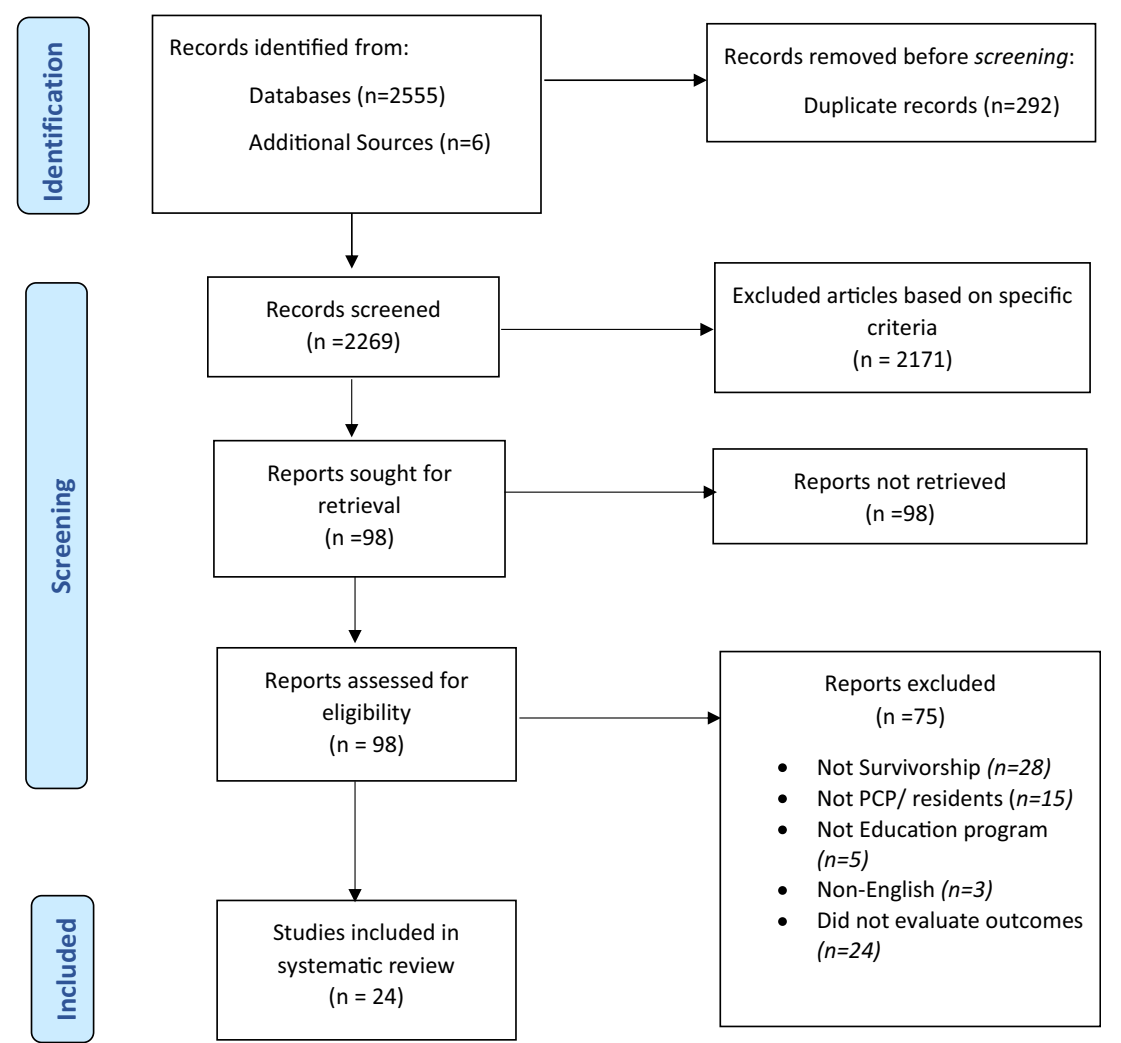

post-test design. Five studies used a post-test only design [41, $47,49,53,54]$, two studies used a mixed-methods approach $[44,52]$, and one study had an unspecified methodology [50]. Of the 21 survivorship education programs evaluated within these studies, 15 were developed in the USA [38, 39, 41-50, 52, 55, 57], three were developed in Australia [51, 56, 58], one in Germany [54], and two in Canada [40, 53]. Target learners for these programs were PCPs or residents in primary care training, including internal medicine residents [46], pediatric physician residents [55], PCPs only [38-43, 45, 47, 48, 51, 56, 58 , and mixed health professional groups including PCPs $[44,49,50,52-54,57]$.

\section{Quality of the evidence}

All studies were susceptible to bias due to the lack of comparison groups. The quality of most pre-test, post-test and post-test studies was rated poor, with one rating fair (see Supplementary File 5). In addition to the inherently high risk of repeat testing bias, observer bias, the Hawthorne effect, and attrition bias of these types of studies, most of these studies presented limited information about eligibility criteria, sample size calculation, loss to follow-up, fidelity of intervention delivery, and the definition and reliability of outcome measures. Of the two mixed-methods studies, one was of high methodological quality [52] and the other received a poor rating [44], presenting issues such as unspecified qualitative methodology, sampling strategy, and statistical methods (see Supplementary 5). Across all studies, outcome measures generally consisted of non-validated self-response measures, increasing risk of self-rater bias. Further, only eight [38-40, 42, 44, 48, 52, 55] of 21 studies included a statistical analysis of results and specified the magnitude of change.

\section{Content and modality of cancer survivorship programs}

Survivorship care components and content of each program are outlined in Table 2. Intended cancer survivorship content differed across education programs and included clinician education targeted towards the management of fear of cancer recurrence [38]; utilization of survivorship care plans (SCPs) $[42,53]$; management of sexual complications in female cancer survivors [48]; survivorship management specifically for Hodgkin's lymphoma, breast cancer and prostate cancer survivors [39], and cervical, breast, and colon cancer survivors [41]; childhood cancer survivors [43, 47, 55]; survivors undergoing immunotherapy [50]; and "general cancer survivorship" across all populations [40, 44-46, 49, 51, 52, 54, 56-58]. A variety of approaches to survivorship education were described across studies including self-directed online courses $[39,45,47,56]$, in-person presentations [38, 42, 58], workshops and training sessions [40, 44, 46, 48, 54, 55], placement and clinical rotation programs [41, 51, 58], a fellowship program [49], a referral program [53], a live 


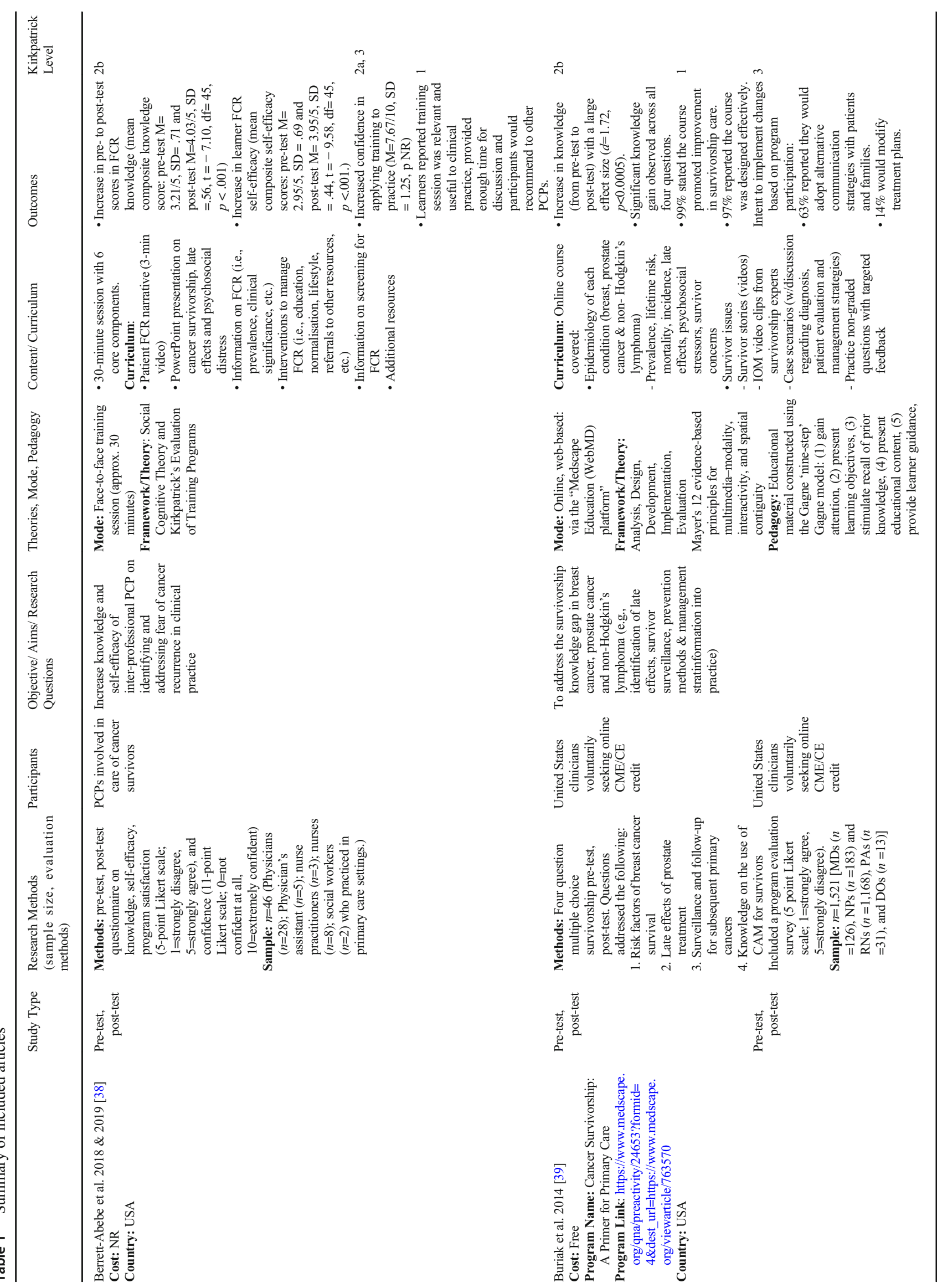




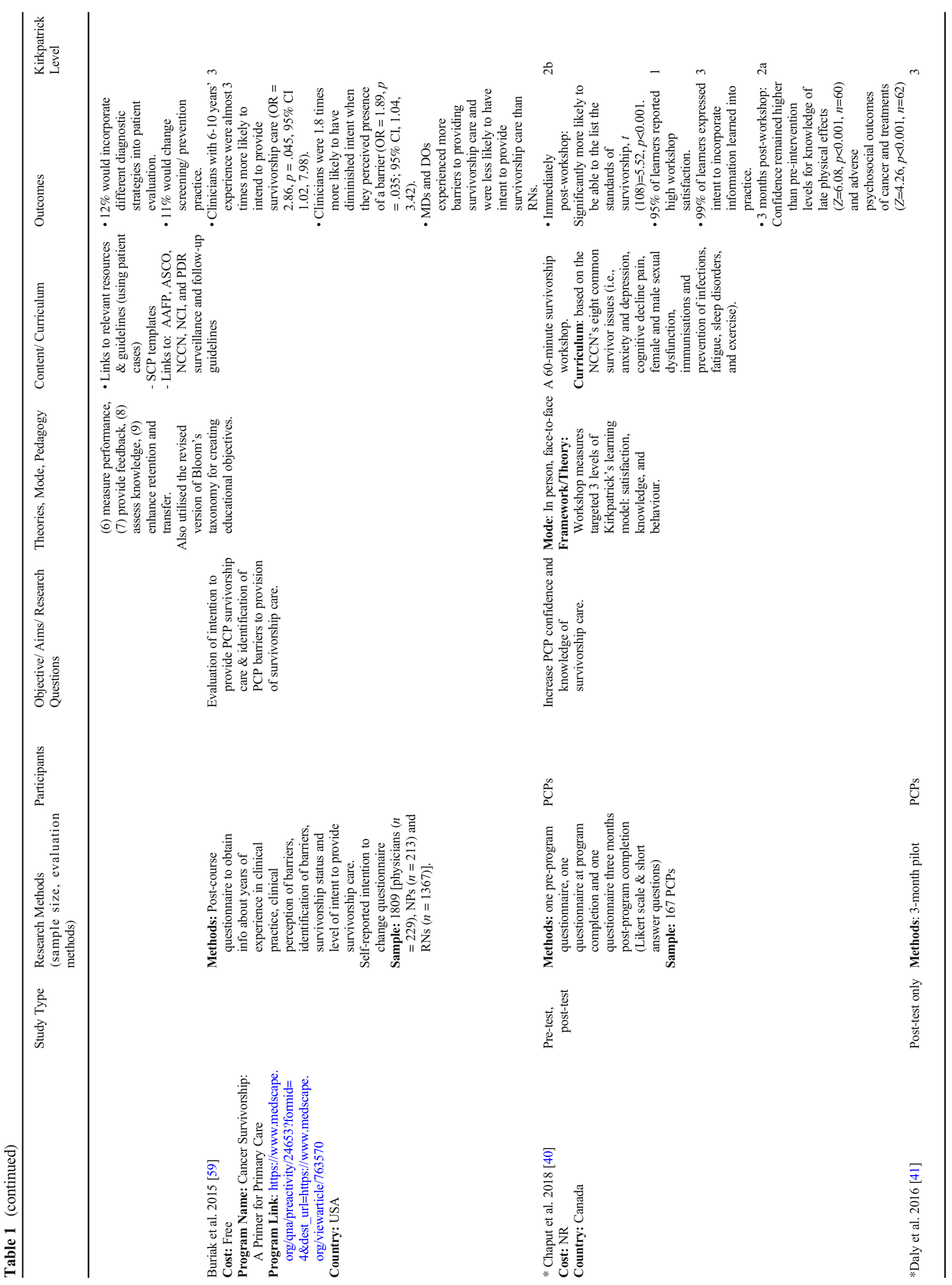




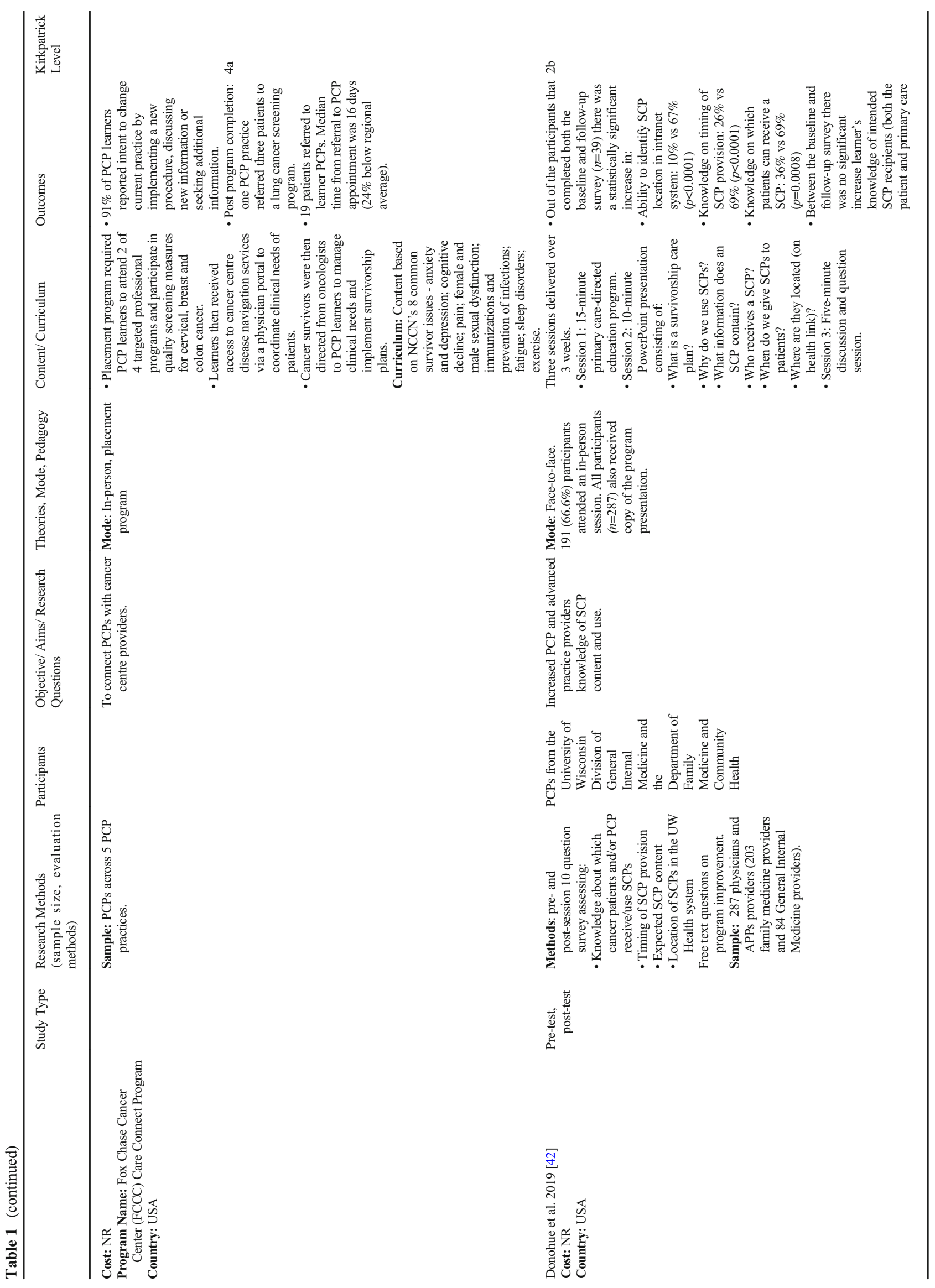




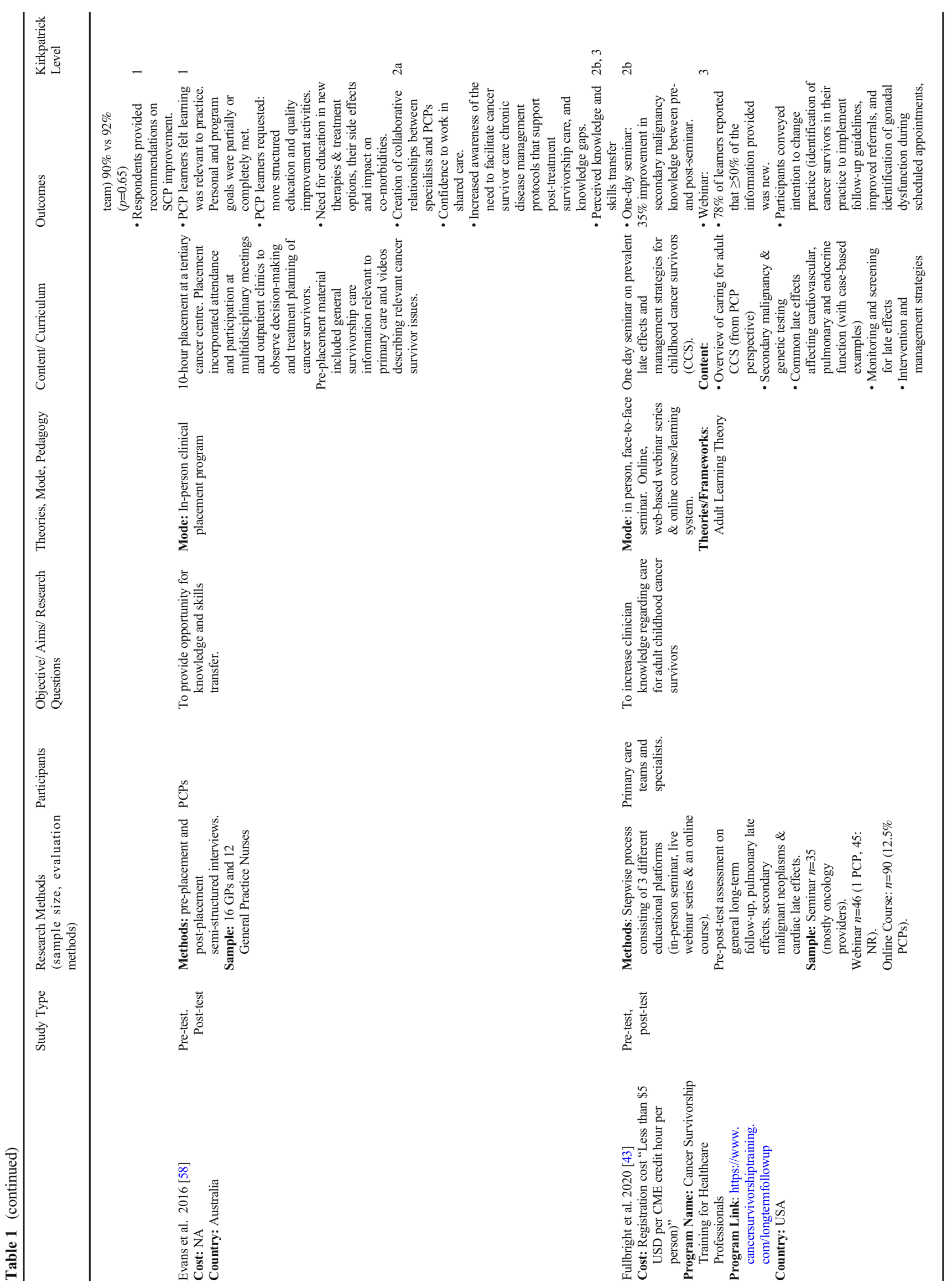




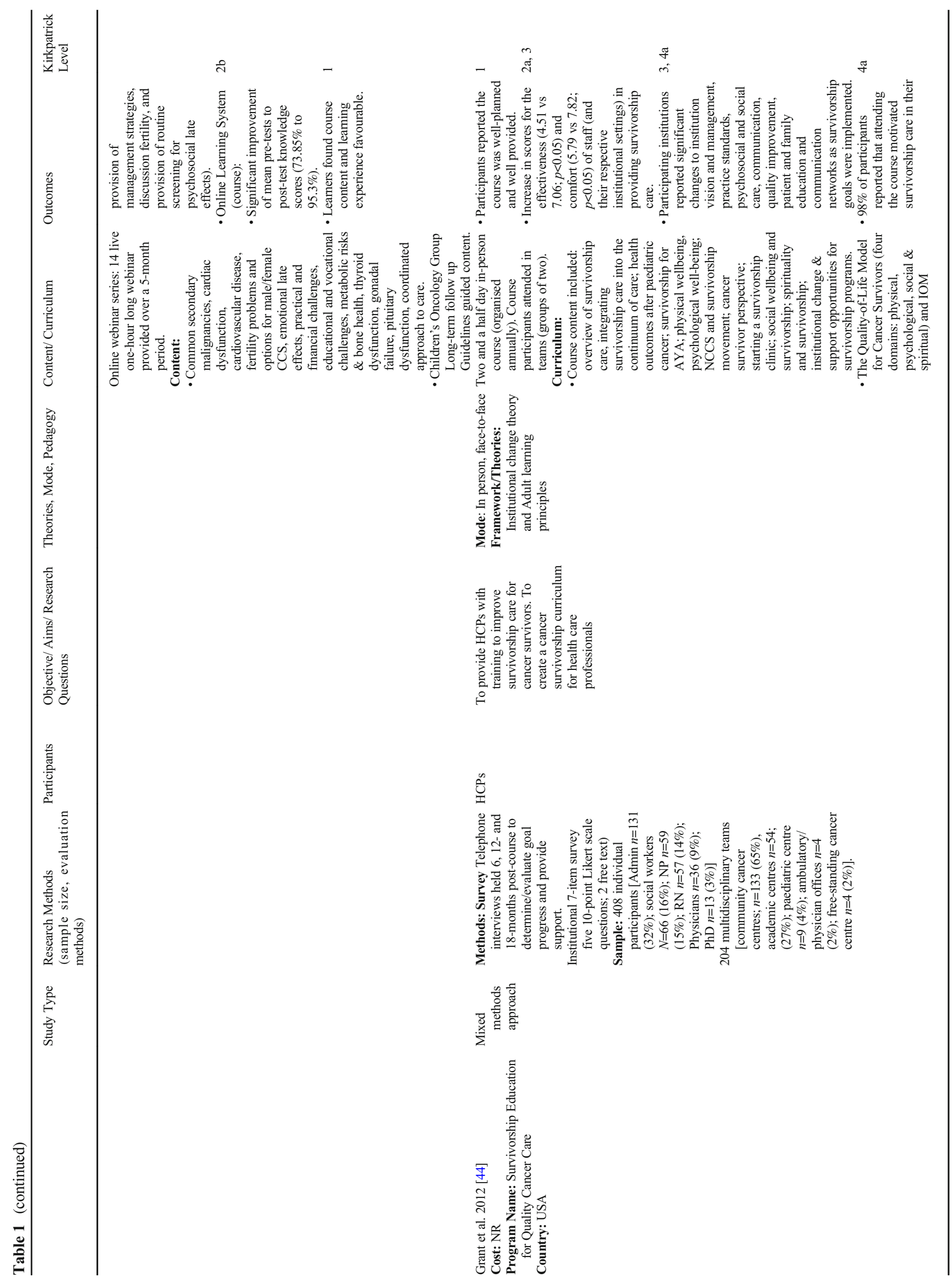




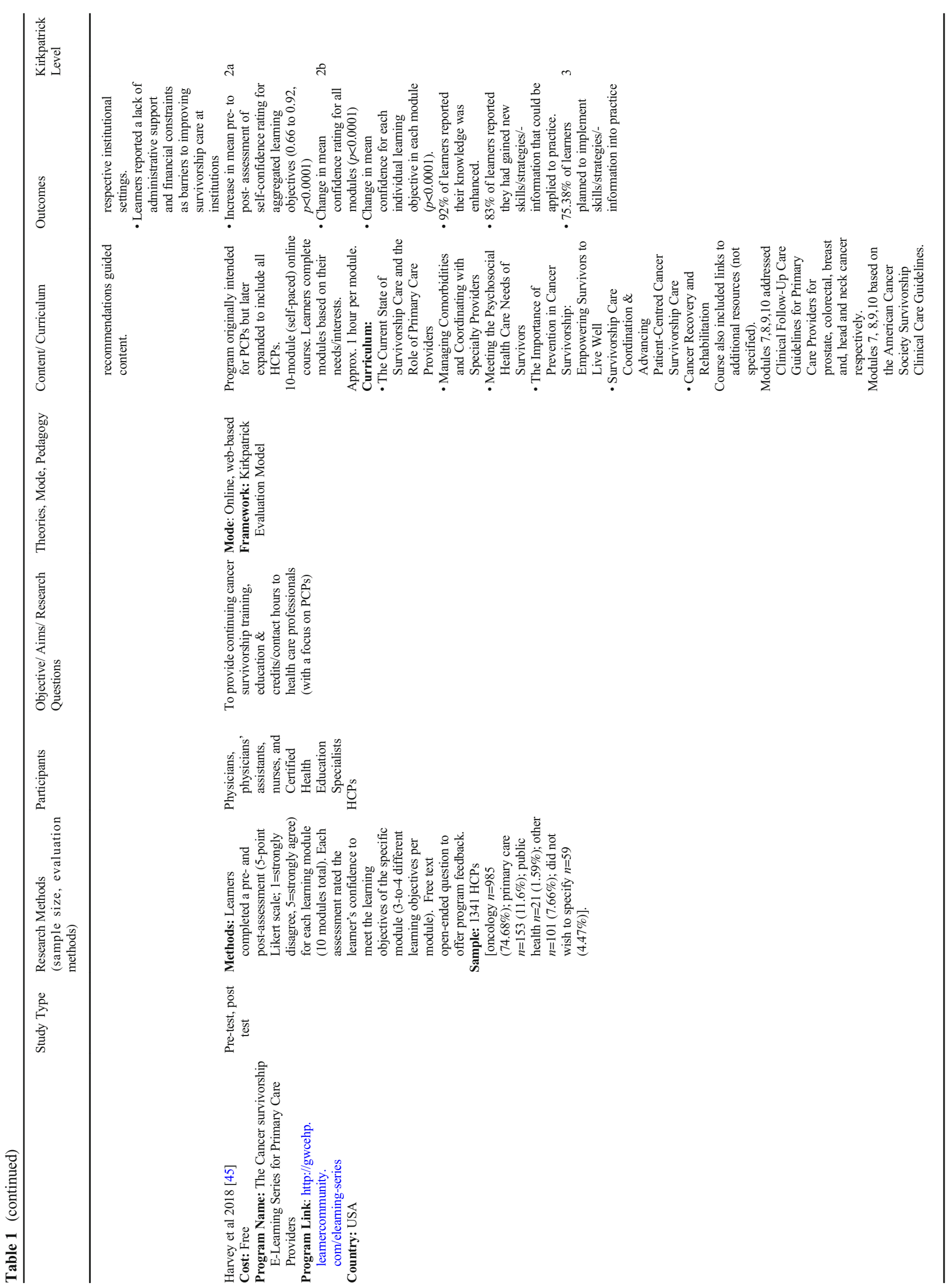




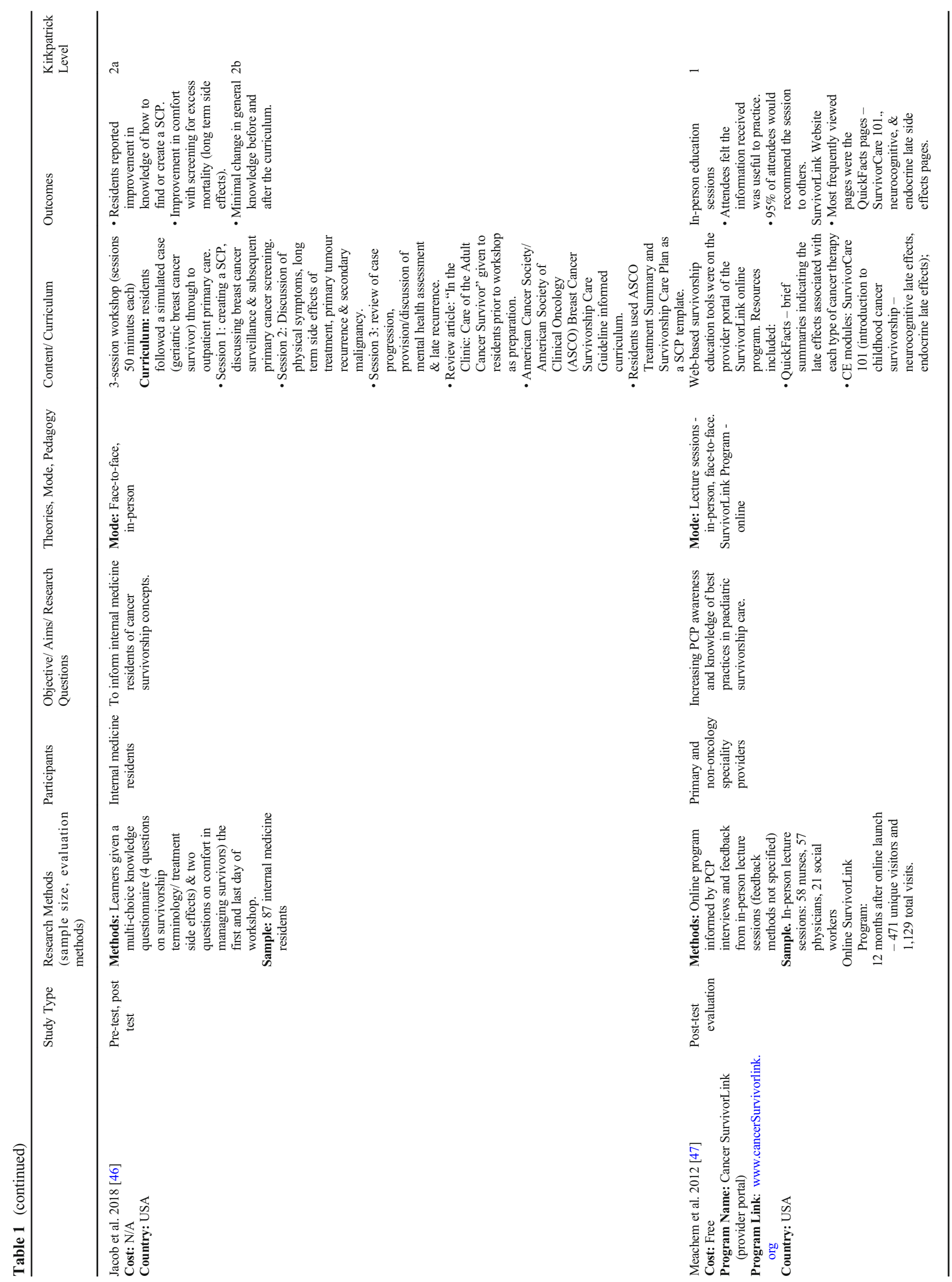




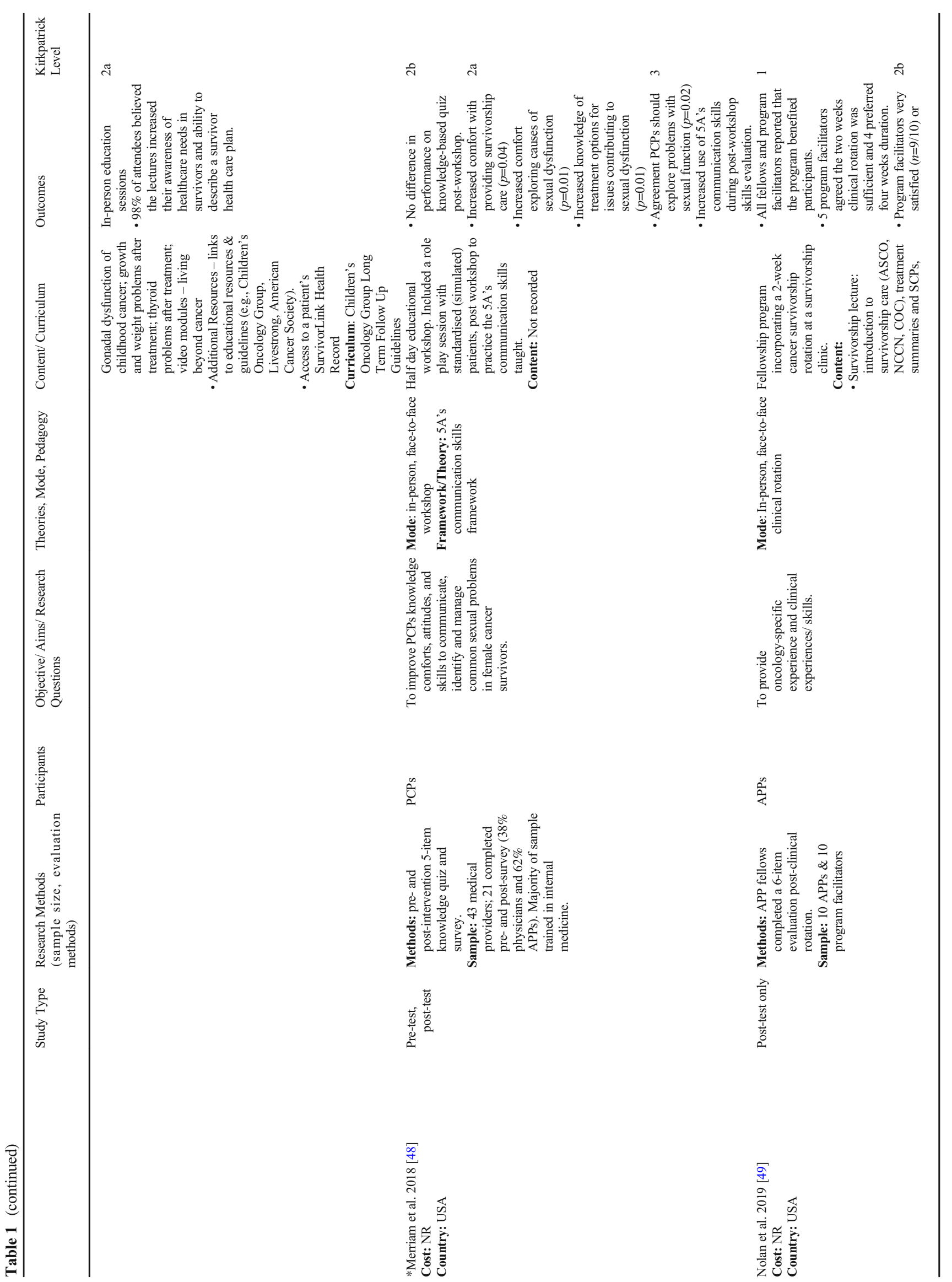




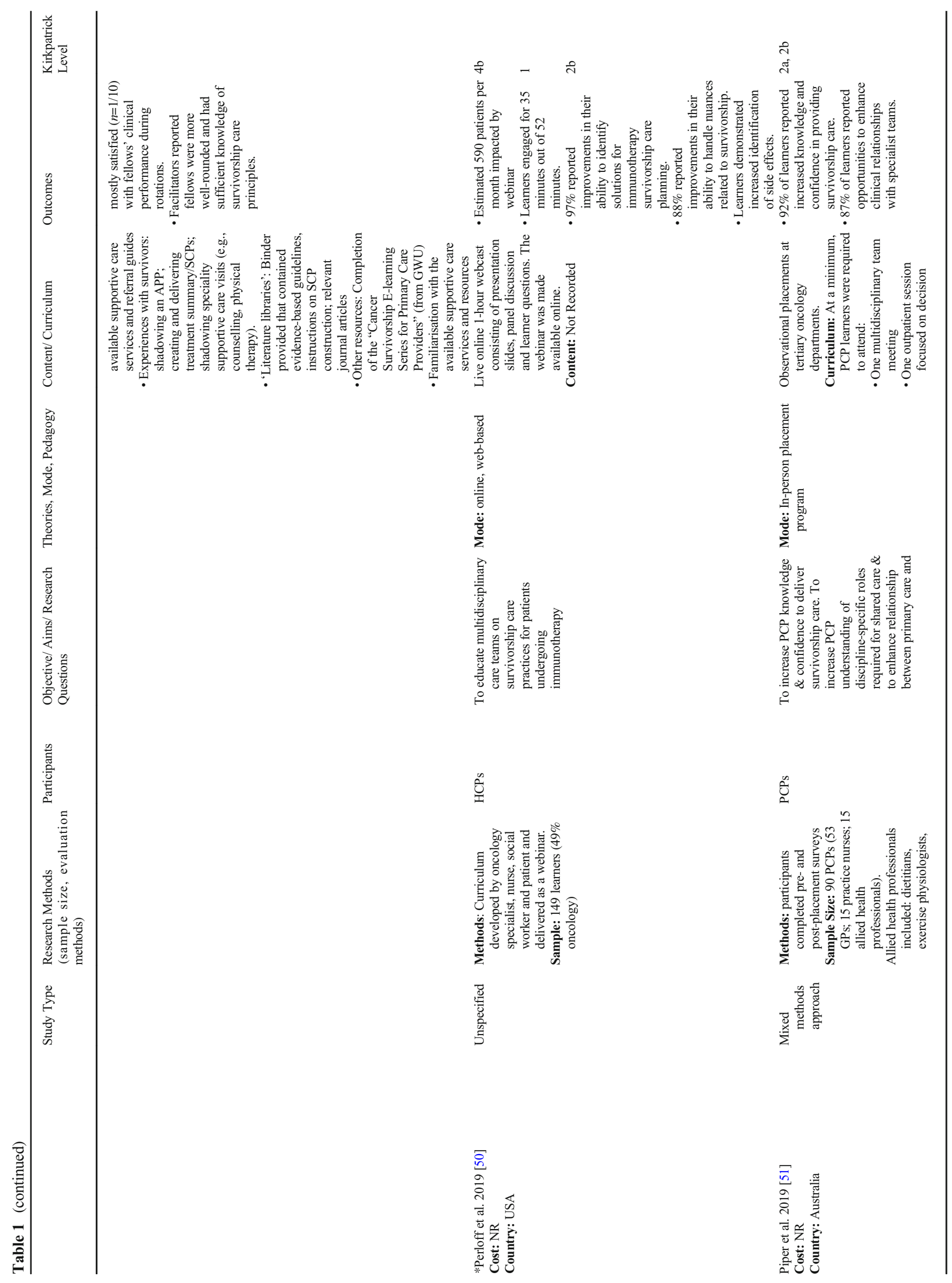




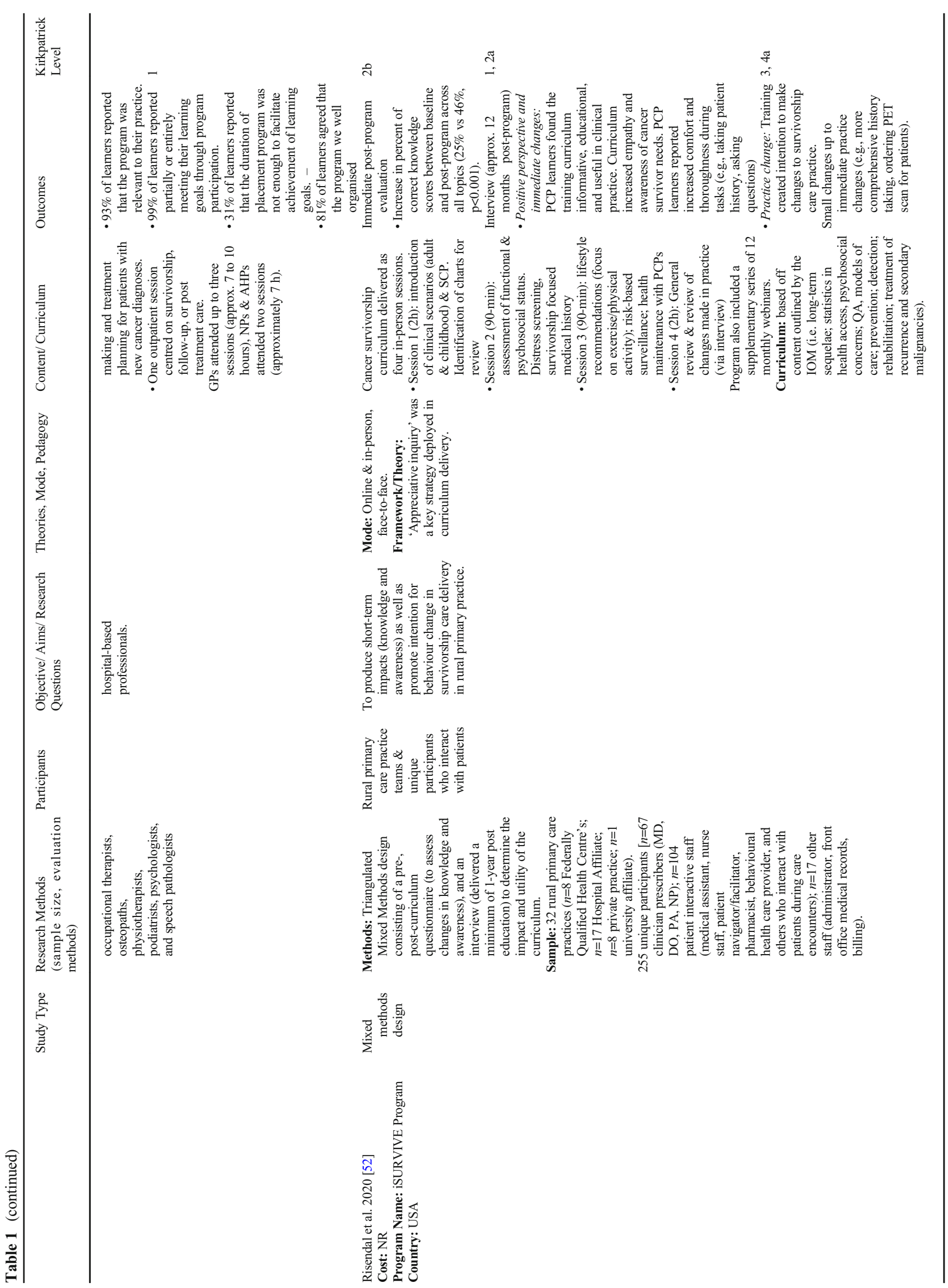




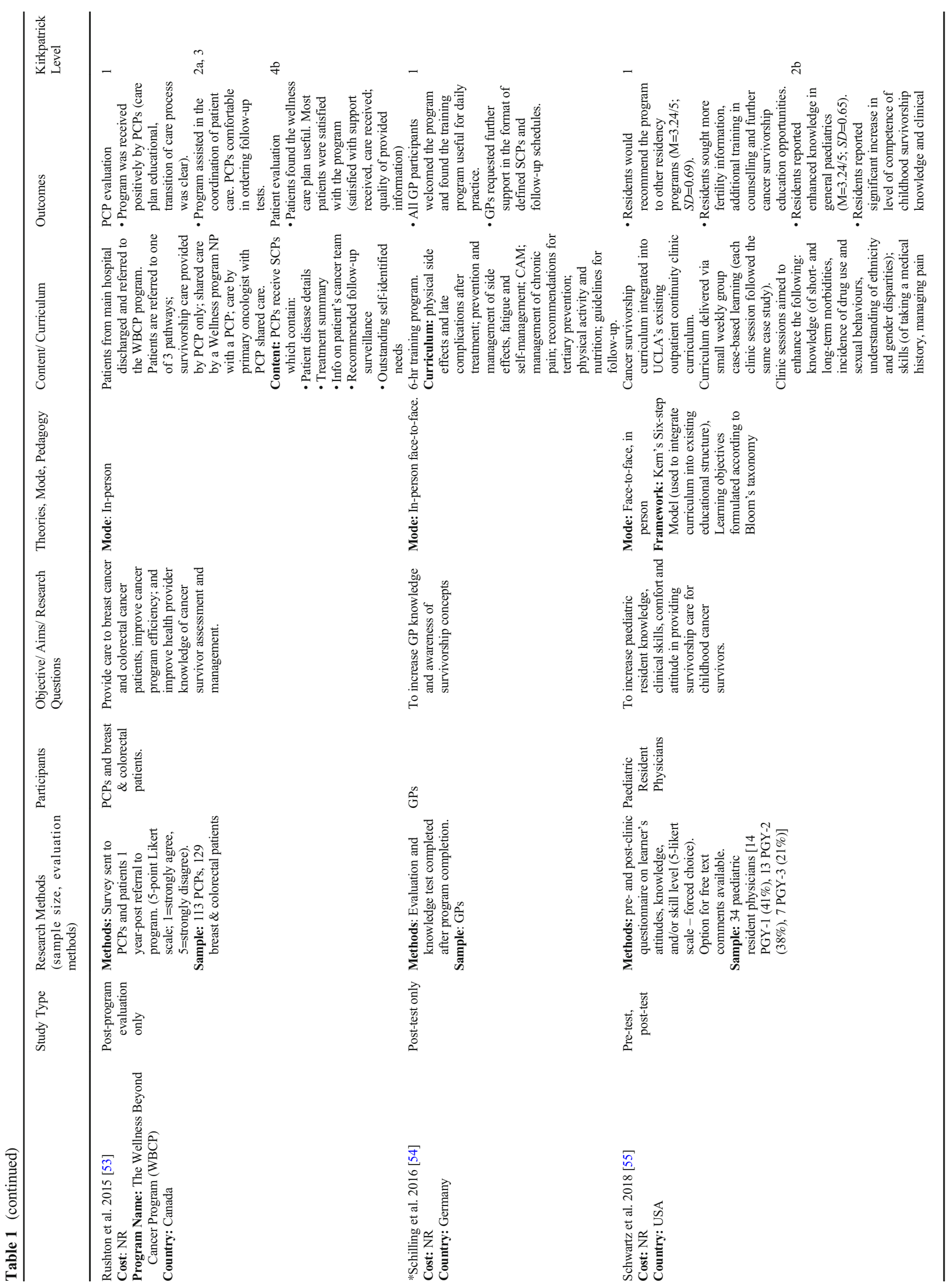




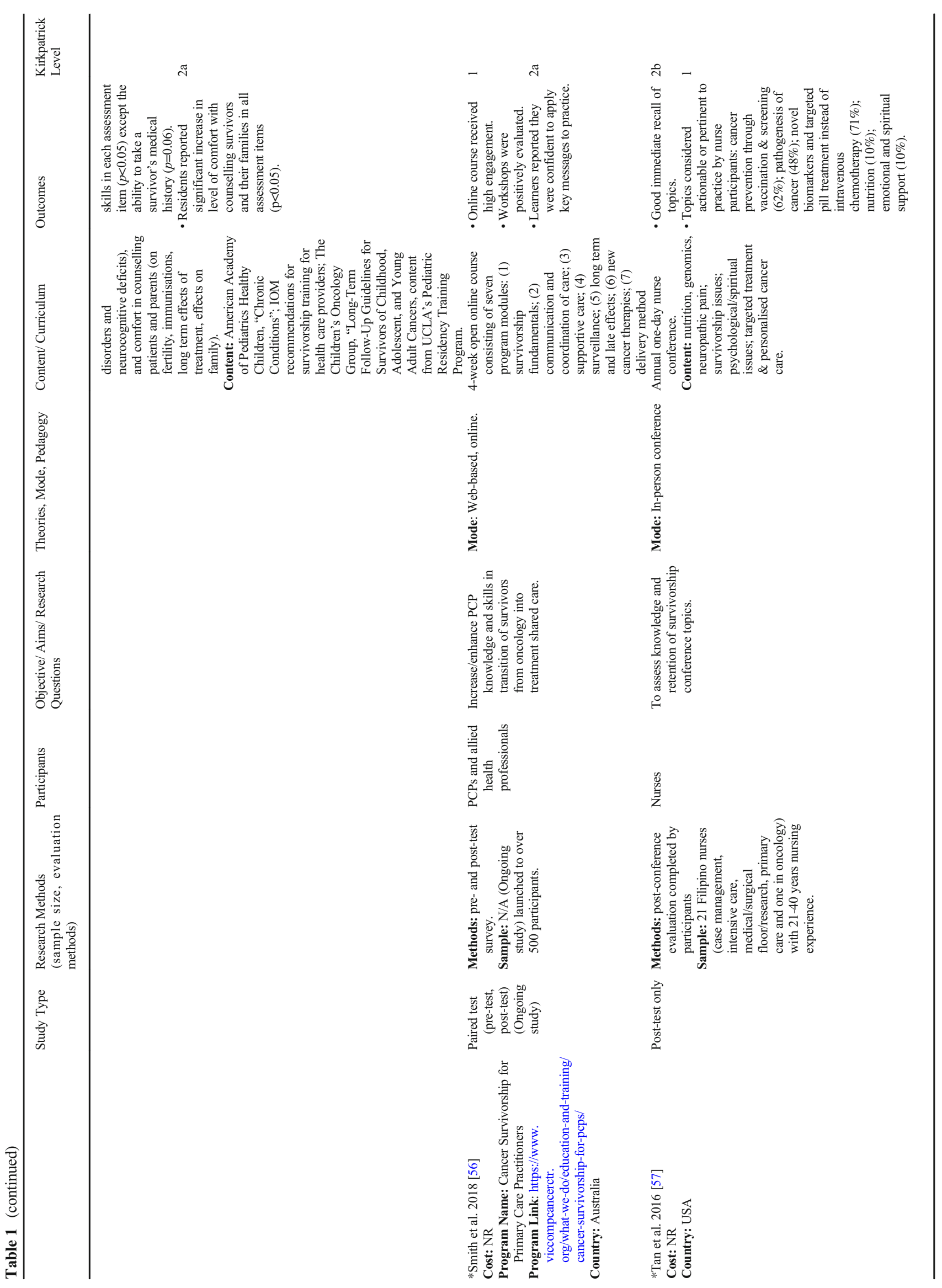




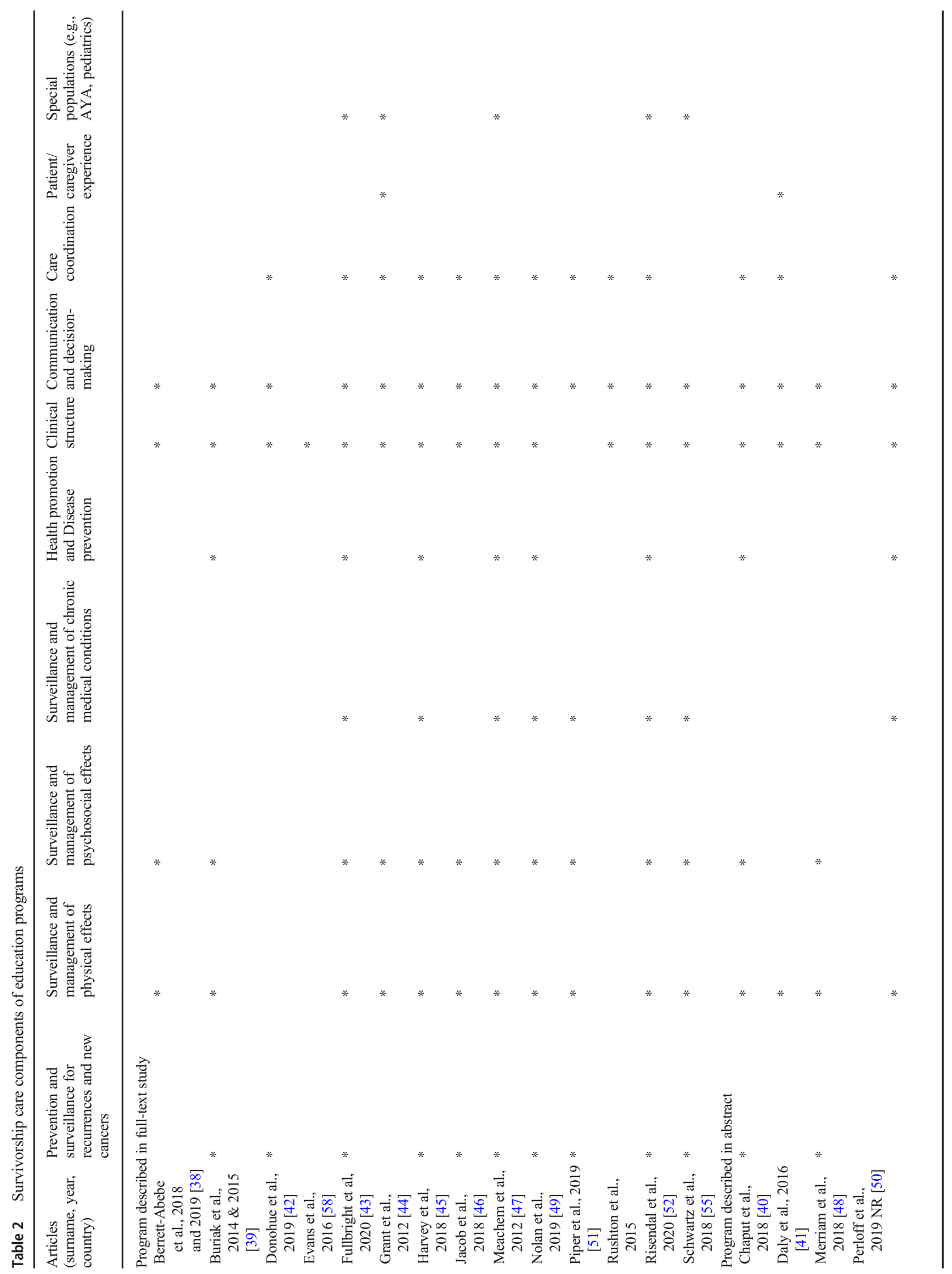




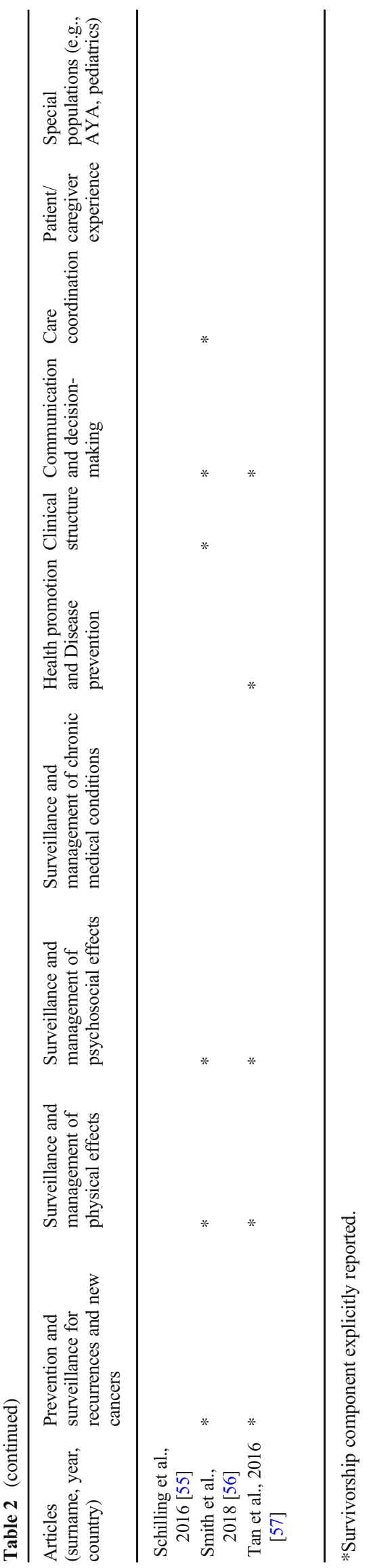

webcast [50], a survivorship conference [57], an in-person workshop and online webinar [52], and an in-person seminar and online webinar series [43].

\section{Cancer survivorship program curricula}

A range of sources and guidelines were used to inform survivorship education curricula and content. Eight [43-48, 52, 55] of 21 programs specified the utilization of at least one specific recognized guideline or framework to inform survivorship program content or curricula. These guidelines/frameworks included the Children's Oncology Group Long-Term Follow-up Guidelines [43, 47, 55]; the Quality of Life Model for Cancer Survivors [44]; the American Cancer Society Clinical Care Guidelines [45]; the American Society of Clinical Oncology (ASCO) Breast Cancer Survivorship Care Guidelines and ASCO Treatment Summary Survivorship Care Plan [46]; the Institute of Medicine (IOM) survivorship recommendations [52]; and the 5A's communication framework [48]. One study [39] did not explicitly specify the foundation of curriculum content but described the utilization of videos from the IOM in their program and linked additional resources from the American Academy of Family Physicians (AAFP), National Comprehensive Cancer Network (NCCN), National Cancer Institute (NCI), the Physicians' Desk Reference (PDR) and ASCO. Lecture content for one fellowship program was informed by the Commission on Cancer (COC), ASCO, and NCCN guidelines [49]. One study described the use of an interdisciplinary committee (incorporating cancer survivor representatives) along with literature, to inform their survivorship curriculum [53]. Two studies engaged clinical stakeholders in informing curricula $[38,50]$, but did not specify the engagement of cancer survivors. One study engaged a stakeholder group consisting of clinicians, community outreach, marketing, and business development staff in informing program curriculum content [41]. Seven studies did not specify what informed survivorship program content or curricula [40, 42, 51, 54, 56-58].

\section{Teaching or learning frameworks and theories underpinning the survivorship programs}

Eight [38-40, 43-45, 52, 55] of 21 survivorship education programs explicitly described the use of a teaching or learning framework or theory to guide program development or evaluation. Buriak and colleagues [39] used the Analysis, Design, Development, Implementation, and Evaluation (ADDIE) instructional systems process model and a revised version of Bloom's taxonomy to design their educational program. The same authors also used Gagne's "Nine Events of Instruction" and Mayer's principles of multimedia modality to facilitate effective learning. Berrett-Abebe, Chaput, Harvey, and colleagues [38, 40, 45] described the use of Kirkpatrick's 
Training Evaluation Framework. Of these three studies, Chaput and colleagues [40] utilized three levels of the framework (satisfaction, knowledge, and behavior) to develop the outcome measures of their education program, and the remaining two studies [38, 45] used the framework to guide program evaluation. Berrett-Abebe and colleagues [38] also described use of social cognitive theory to guide the development of their training program. Fulbright and colleagues [43] used adult learning theory in curriculum development (and in case-based examples). Grant and colleagues [44] described the utilization of adult learning principles and institutional change theory. Risendal and colleagues [52] utilized Boot Camp Translation methodology and appreciative inquiry to develop and implement their curriculum, while Schwartz and colleagues [55] used Kern's six-step model to integrate their survivorship curriculum into an existing educational structure. The same study also used Bloom's taxonomy to inform learning objectives. Thirteen studies [41, 42, 46-51, $53,54,56,57]$ did not describe the use of a teaching or learning framework/theory.

\section{Cancer survivorship program evaluation}

Education program outcomes are reported in Table 1 as informed by the Kirkpatrick framework. Program outcomes and final interpretations were the same after removal of abstract studies from analysis; thus, outcomes described in full-text papers and conference abstracts were appropriate to be combined during narrative synthesis.

\section{Kirkpatrick level 1 -reaction to program}

Sixteen studies [38-40, 42-44, 46, 47, 49, 51-55, 57, 58] evaluated level 1 outcomes. Views on learning experience were mostly measured using a Likert scale (from strongly disagree to strongly agree) with certain studies also incorporating open text $[42,44,55]$ and interview feedback $[44,47$, 52, 53, 58]. Across all 16 survivorship programs, learner experience and program content were generally reported to be favorable. Outcomes reported included program usefulness and relevance to practice [38, 47, 51, 52, 54, 55, 57]; satisfaction with program design and organization $[39,51]$; satisfaction with program content and delivery [39, 40, 43, 44, 49, 51, $53,58]$; recommendations for program improvement $[42,58]$; and the recommendation of the program to others [38, 46, 55]. Critical reports on learning experience included insufficient program duration to facilitate the achievement of learning goals [51, 58]; the request for further training in survivorship counseling, additional onco-fertility information, and survivorship training opportunities [55]; limited exposure to long-term follow-up care and the request for more structured education and quality improvement activities [58]; and additional support in acquiring well-defined SCPs and follow-up schedules [54].

\section{Kirkpatrick level 2-learning}

Thirteen studies [38, 40, 44-48, 51-53, 55, 56, 58] reported positive level 2 a outcomes, including increased awareness of cancer survivor needs $[47,52,58]$ and increased confidence [38, 40, 45, 51, 56, 58], self-efficacy [38], and comfort [44, $46,48,52,53,55]$ in providing cancer survivorship care. Most outcomes were measured using self-reported questionnaires with three studies utilizing interviews [44, 52, 58]. Fourteen studies [38-40, 42, 43, 45, 46, 49-52, 55, 57, 58] evaluated level $2 \mathrm{~b}$ outcomes assessing improvements in knowledge, competency [55], and the recall of topics [57]. Eleven of the fourteen studies evaluated knowledge outcomes using pretests and post-tests that were delivered immediately after program cessation (immediate post-test) (e.g. questionnaires, surveys); two studies used a pre-test and immediate post-test followed by a 3 month [40] or 12 month [52] delayed posttest; and one study utilized feedback from fellowship program facilitators to determine that learners had sufficient increase in cancer survivorship knowledge [49].

\section{Kirkpatrick level 3-transfer of learning/behavior change}

Nine studies [38, 39, 41, 43, 44, 48, 52, 53, 58] evaluated PCP learner behavior change as a result of survivorship education. Of the eight studies, only two $[44,53]$ evaluated the transfer of cancer survivorship learning to clinical practice (e.g., increased PCP confidence ordering follow-up tests; selfreported behavior change due to education intervention), both of which also provided follow-up evaluation 12 months postprogram commencement. The remaining six studies [38, 39, $41,43,48,52,58]$ only measured outcomes immediately postprogram; and thus, only evaluated the intention of PCPs to change practice (e.g., implement follow-up guidelines, improve referrals, provision of routine screening, etc.).

\section{Kirkpatrick level 4-program impact/results}

Two studies evaluated level 4 a outcomes assessing survivorship changes in organizational practice [41, 44]. Daly and colleagues [41] reported that one PCP practice referred three patients onto lung surveillance and screening because of PCP education sessions within their program. Nearly all $(98.1 \%)$ participants in Grant and colleagues study [44] reported that program participation resulted in the uptake of cancer survivorship care at their respective institutions, though specific detail on changes were not provided. Institutional assessments and surveys completed 18-month post-program commencement found significant change and improvement in organization vision and management standards; practice standards; 
psychosocial, emotional, and social care; communication standards; quality improvement standards; patient and family education; and community network partnerships. However, despite reporting statistical significance, the specific magnitude of change was unclear.

Three studies $[50,52,53]$ assessed level $4 \mathrm{~b}$ outcomes which indicate survivorship program impact at the patient level. Risendal and colleagues' mixed-methods study [52] found that training sessions led to varied survivorship care changes across participating rural practices, including more comprehensive history taking, improved referral of patient surveillance scans, and other unspecified immediate changes. Rushton and colleagues [53] reported that 1 year after initial transfer to their PCP cancer survivorship referral program, patients were satisfied with the overall support, care, and quality of information received and were more knowledgeable about treatment received, potential late effects, and the latent symptoms to report to their primary care providers. Perloff and colleagues [50] estimated that 590 patients per month were "impacted" by their PCP survivorship webinar; however, it was not specified how authors measured this outcome or whether the impact was positive or negative. Notably, all three studies $[50,52,53]$ did not quantify the magnitude of change in outcomes reported.

\section{Discussion}

Primary care providers are integral in the provision of acute and follow-up care to cancer survivors, yet many PCPs report being unprepared to offer adequate cancer survivorship care. To our knowledge, this is the first systematic review evaluating cancer survivorship education programs targeted towards PCPs in published literature.

\section{Cancer survivorship program content}

Survivorship program content and aims varied across studies with some programs focusing on specific symptoms (e.g., fear of cancer recurrence) or cancer groups (e.g., neurological cancers) and other programs providing a more complete overview of survivorship care. In an ideal circumstance, PCPs should have access to high quality programs that provide a broad overview of survivorship, as well as those that focus on a specialized topic such as management of specific symptoms. While it is recommended that survivorship education programs for PCPs address all core survivorship competencies $[9,33]$ (e.g., surveillance for recurrence and second malignancies, management of late and long-term effects, management of psychosocial wellbeing, and health promotion), it is essential that the specific programs are "pitched" at the right level for the targeted PCPs. Risendal and colleagues [52] raised the possibility that the curriculum developed for their PCP cancer survivorship training program can be too broad and that important learning points may not have been emphasized strongly enough; as despite improving from baseline, PCP learners still recorded "poor" test results. In contrast, overcomplexity can be a key barrier to learning uptake through hindering information recall and limiting the transfer of learnings to practice [60]. Therefore, a one-size-fits-all approach is likely inappropriate. To address this issue, an evidence-based approach to establish the minimum cancer survivorship educational requirements needed for PCPs is crucial. Moreover, the ASCO Core Curriculum for Cancer Survivorship Education [33] could potentially provide a framework which could be contextualized to the scope and practice of PCPs. Additionally, comprehensive survivorship education programs should be made adaptable to the local context and learning needs of individual PCPs (e.g., determination of prior knowledge, adaptation of content to learning characteristics, adaptive navigation, altering the sequence of program content) to improve learning outcomes $[61,62]$.

In the 21 included studies, only 14 studies described the sources used to inform survivorship content or curricula. Of the 14 studies, only eight studies specified the use of recognized survivorship guidelines. To ensure PCPs are competent in survivorship care, it is paramount that education programs are based on current, quality evidence. While we acknowledge that information on content development is often omitted from publication, study authors should endeavor to highlight education content is evidenced-based, to increase learner confidence in program quality.

\section{Teaching and learning approaches}

The use of learning and teaching theories across all twentyone survivorship programs were minimal, with only eight studies describing the use of a specific learning framework to guide program development. The ultimate aim of survivorship education programs is to facilitate clinical behavior change that will impact the care of cancer survivors $[63,64]$. Greater attention is needed to incorporate behavior learning frameworks and theories into survivorship programs to promote tangible and sustainable changes in clinician practice $[7,65]$.

Our systematic review also identified that cancer survivorship programs can be delivered in a variety of modalities (fellowship programs, online modules, didactic lectures, presentation, workshops, etc.) depending on needs and context — all resulting in perceived positive learning outcomes. While this review does not allow the comparison of the efficacy of different learning modalities, the choice of delivery mode for any education program can directly impact learning outcomes and knowledge retention. Further investigation of the impact of various learning and teaching approaches in the context of cancer survivorship education is required [60,61]. For 
example, in a recent review on cancer education in medical schools [66], education programs which promoted interactive educational experiences such as clinical simulation, role play, summer programs, and interaction with multidisciplinary teams were highly effective and had the most positive impact on learners, while intensive block programs, lectures, small group discussions, and computer or web-based education were not as effective [66]. Additionally, when compared to traditional learning, web-based education programs have been shown to have little to no difference on health professionals' knowledge and behaviors or outcomes of patients [67].

Although interactive survivorship education programs may be ideal, lack of clinician time has been highlighted as a significant barrier to PCP delivery of cancer survivorship care $[14,68]$, with providers indicating a preference for online programs [69]. Another consideration is the rapid development and innovation in learning technology and access limitations as a result of the COVID-19 pandemic [70]. Interestingly, twelve survivorship education programs in our review were delivered over 1 day or more with reported learner satisfaction and positive feedback - suggesting that PCPs are also willing to dedicate ample time to survivorship learning. As the current literature in this area does not allow evaluation of the most optimal mode of delivery, future research should be conducted to identify the optimal and most appropriate modality depending on needs, context, and setting to ensure practical consideration are accounted for, content is tailored to the appropriate primary care audience, and that positive learning outcomes are amplified. In particular, survivorship program developers seeking to introduce additional modalities to existing programs (particularly in residency programs) should regularly measure program learning outcomes through education assessments (at a minimum pre- and posteducation), differentiate assessment results by modality, and then examine any differences in performance [71].

\section{Cancer survivorship program outcomes}

Learning outcomes (e.g., PCP satisfaction, transfer of behavior change, knowledge, confidence) across all 21 programs were generally reported to favorable and beneficial to PCPs. While promising, it should be noted that most studies only assessed outcomes immediately after program completion, meaning the long-term impact of survivorship education on clinical practice was not evaluated. For instance, although nine of 21 programs reported that PCPs had increased willingness and intent to change practice, only two studies actually evaluated whether PCP learners had implemented the skills learned during survivorship education into practice. Similarly, few studies evaluated the impact of survivorship education programs on organizational practice $(n=3)$ and patient outcomes $(n=2)$; and those that did, did not quantify or provide evidence of these results. These deficiencies highlight the need for more rigorous and robust study designs that incorporate adequate follow-up to better identify the long-term impact of survivorship programs on survivorship care delivery and PCP behavioral change.

\section{Limitations}

Several limitations of this systematic review exist. First, all included studies were published in English, and most included cancer survivorship programs were developed in the USA. Therefore, such programs may not be applicable for other use in other countries especially countries where the culture, language, and health systems are vastly different. Second, while it is common in the education literature, the high risk of bias across the included studies (due to self-reporting, lack of follow-up testing, study design, etc.) suggests that caution should be taken when interpreting the findings from these studies. Nevertheless, this review provides some direction for future research in this area. Third, only the published literature was searched for this review, and hence, we did not include many educational programs, both in-person and online that have been developed and conducted over the past decade (e.g., ASCO Continuing Medical Education). Although this approach limits the inclusion of such programs, the lack of detailed evaluation data available for these programs in a published report precludes us from addressing the aim of this review.

\section{Future implications and conclusions}

A plethora of cancer survivorship education programs targeted towards PCPs currently exist; however, we could only identify 21 studies that evaluated education outcomes in the published literature in this review. In Fig. 2, we propose the following recommendations for developing and evaluating survivorship education program. Our review highlights significant limitations of existing survivorship programs; therefore, we suggest that survivorship education program content should be based on evidence-based survivorship frameworks and incorporate evidence-based learning and teaching approaches. Further, survivorship program content should be tailored to PCPs through the establishment of minimum educational requirements to increase the utility and relevance of survivorship education to primary care practice. Additionally, our literature search highlighted extensive duplication of content across PCP survivorship education programs. While acknowledging the necessity of contextual considerations (e.g., profit, prestige, varying health systems), we posit that education developers should first identify other appropriate 


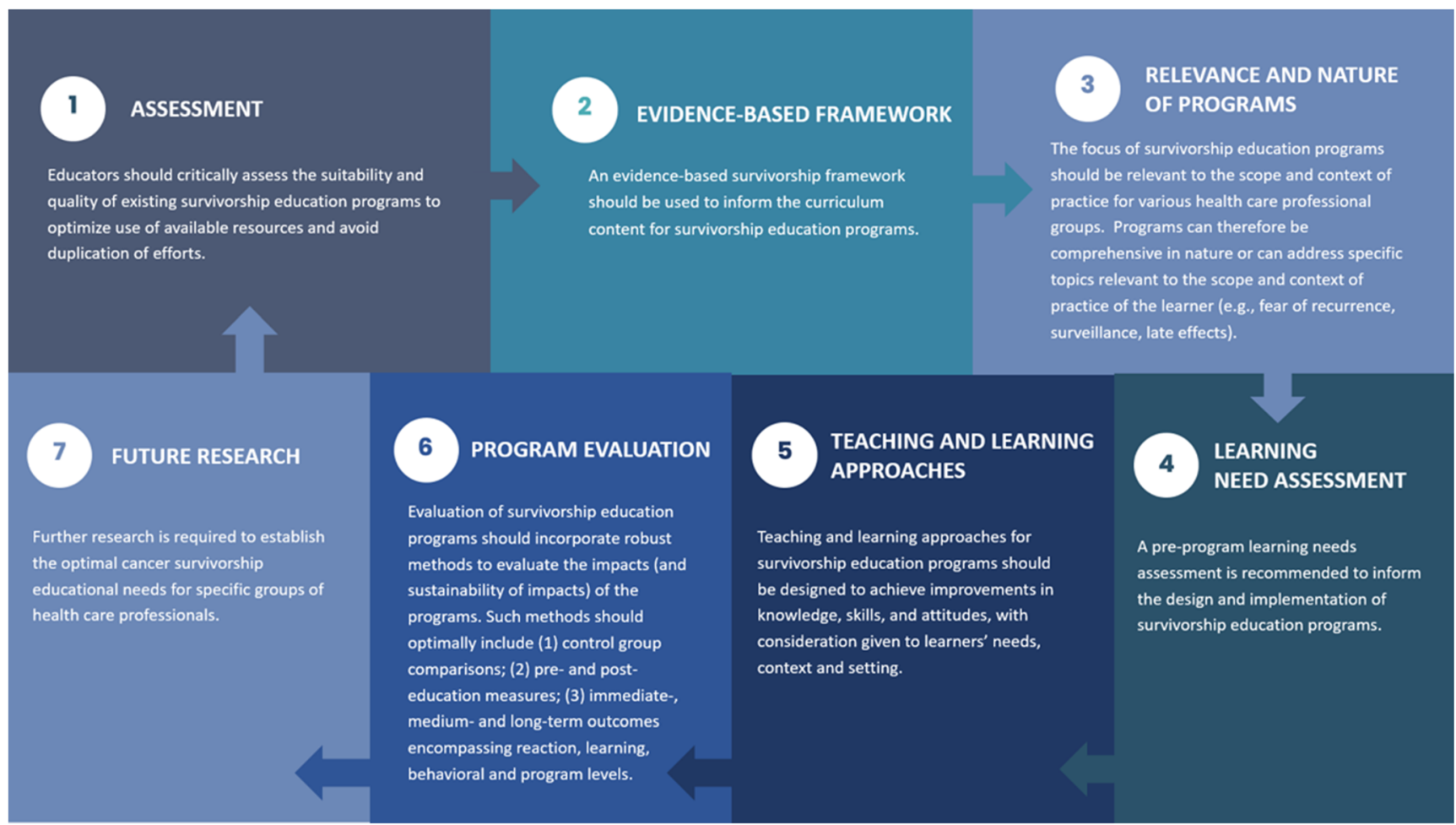

Fig. 2 Recommendations for developing and evaluating survivorship education program

education programs before "re-inventing the wheel" and duplicating efforts. Further collaborative efforts should be dedicated to the development of studies which incorporate robust evaluations of survivorship programs and measure the impact (and sustainability of impacts) of education on survivorship care delivery and patient outcomes.

Supplementary Information The online version contains supplementary material available at https://doi.org/10.1007/s11764-021-01018-6.

Author contribution All authors made substantial contributions to the interpretation of data; drafting the article or revising it critically for important intellectual content; and final approval of the version to be submitted.

Funding RJC receives salary support from the National Health and Medical Research Council (NHMRC) through an NHMRC Investigator Grant (APP1194051)

Data Availability Not applicable.

Code availability Not applicable.

\section{Declarations}

Ethics approval Not applicable.
Consent to participate Not applicable.

Consent for publication Not applicable.

Competing interests The authors declare no competing interests.

\section{References}

1. Ferlay J, Ervik M, Colombet M, Mery L, Pineros M. Global cancer observatory: cancer today. 2019.

2. Bray F, Jemal A, Grey N, Ferlay J, Forman D. Global cancer transitions according to the Human Development Index (2008-2030): a population-based study. Lancet Oncol. 2012;13(8):790-801.

3. Leach CR, Weaver KE, Aziz NM, Alfano CM, Bellizzi KM, Kent EE, et al. The complex health profile of long-term cancer survivors: prevalence and predictors of comorbid conditions. J Cancer Surviv. 2015;9(2):239-51.

4. Erikson C, Salsberg E, Forte G, Bruinooge S, Goldstein M. Future supply and demand for oncologists: challenges to assuring access to oncology services. J Oncol Pract. 2007;3(2):79-86.

5. Mathew A. Global survey of clinical oncology workforce. J Global Oncol. 2018;4:1-12.

6. Yang W, Williams JH, Hogan PF, Bruinooge SS, Rodriguez GI, Kosty MP, et al. Projected supply of and demand for oncologists and radiation oncologists through 2025: an aging, better-insured population will result in shortage. J Oncol Pract. 2014;10(1):39-45.

7. Chaput G, Med CP, Sussman J. Integrating primary care providers through the seasons of survivorship. Curr Oncol (Toronto, Ont). 2019;26(1):48-54.

8. Io M. From cancer patient to cancer survivor: lost in transition. Washington: Institute of Medicine 2005. 
9. Nekhlyudov L, O'Malley DM, Hudson SV. Integrating primary care providers in the care of cancer survivors: gaps in evidence and future opportunities. Lancet Oncol. 2017;18(1):e30-8.

10. Runowicz CD, Leach CR, Henry NL, Henry KS, Mackey HT, Cowens-Alvarado RL, et al. American Cancer Society/American Society of Clinical Oncology Breast Cancer Survivorship Care Guideline. J Clin Oncol. 2015;34(6):611-35.

11. Cohen EE, LaMonte SJ, Erb NL, Beckman KL, Sadeghi N, Hutcheson KA, et al. American Cancer Society Head and Neck Cancer Survivorship Care Guideline. CA Cancer J Clin. 2016;66(3):203-39.

12. Rubin G, Berendsen A, Crawford S, Dommett R, Earle C, Emery J, et al. The expanding role of primary care in cancer control. Lancet Oncol. 2015;16:1231-72.

13. Maly RC, Liu Y, Diamant AL, Thind A. The impact of primary care physicians on follow-up care of underserved breast cancer survivors. J Am Board Fam Med. 2013;26(6):628-36.

14. Lawrence RA, McLoone JK, Wakefield CE, Cohn RJ. Primary care physicians' perspectives of their role in cancer care: a systematic review. J Gen Intern Med. 2016;31(10):1222-36.

15. Ngune I, Jiwa M, McManus A, Hughes J. Do patients with longterm side effects of cancer treatment benefit from general practitioner support? A literature review. Int J Integr Care. 2015;15:e023.

16. Grunfeld E, Levine MN, Julian JA, Coyle D, Szechtman B, Mirsky $\mathrm{D}$, et al. Randomized trial of long-term follow-up for early-stage breast cancer: a comparison of family physician versus specialist care. J Clin Oncol. 2006;24(6):848-55.

17. Cooper JM, Loeb SJ, Smith CA. The primary care nurse practitioner and cancer survivorship care. J Am Acad Nurse Pract. 2010;22(8):394-402.

18. Vos JAM, Wieldraaijer T, van Weert HCPM, van Asselt KM. Survivorship care for cancer patients in primary versus secondary care: a systematic review. J Cancer Surviv. 2021;15(1):66-76.

19. Dawes AJ, Hemmelgarn M, Nguyen DK, Sacks GD, Clayton SM, Cope JR, et al. Are primary care providers prepared to care for survivors of breast cancer in the safety net? Cancer. 2015;121(8): 1249-56.

20. Suh E, Daugherty CK, Wroblewski K, Lee H, Kigin ML, Rasinski $\mathrm{KA}$, et al. General internists' preferences and knowledge about the care of adult survivors of childhood cancer. Ann Intern Med. 2014;160(1):11-7.

21. Salz T, Oeffinger KC, Lewis PR, Williams RL, Rhyne RL, Yeazel MW. Primary care providers\&\#039; needs and preferences for information about colorectal cancer survivorship care. J Am Board Fam Med. 2012;25(5):635-51.

22. Sima JL, Perkins SM, Haggstrom DA. Primary care physician perceptions of adult survivors of childhood cancer. J Pediatr Hematol Oncol. 2014;36(2):118-24.

23. Bober SL, Recklitis CJ, Campbell EG, Park ER, Kutner JS, Najita JS, et al. Caring for cancer survivors: a survey of primary care physicians. Cancer. 2009;115(18 Suppl):4409-18.

24. Stephens C, Klemanski D, Lustberg MB, Noonan AM, Brill S, Krok-Schoen JL. Primary care physician's confidence and coordination regarding the survivorship care for older breast cancer survivors. Support Care Cancer. 2021;29(1):223-30.

25. Berkowitz C, Allen DH, Tenhover J, Zullig LL, Ragsdale J, Fischer $\mathrm{JE}$, et al. Knowledge and preferences of primary care providers in delivering head and neck cancer survivorship care. J Cancer Educ. 2018;33(6):1323-7.

26. Nissen MJ, Beran MS, Lee MW, Mehta SR, Pine DA, Swenson KK. Views of primary care providers on follow-up care of cancer patients. Fam Med. 2007;39(7):477-82.

27. Price ST, Berini C, Seehusen D, Mims LD: Cancer survivorship training in family medicine residency programs. J Cancer Surviv 2020 https://doi.org/10.1007/s11764-020-00966-9.
28. Susanibar S, Thrush CR, Khatri N, Hutchins LF. Cancer survivorship training: a pilot study examining the educational gap in primary care medicine residency programs. J Cancer Surviv. 2014;8(4): 565-70.

29. Yip SM, Meyers DE, Sisler J, Wycliffe-Jones K, Kucharski E, Elser $\mathrm{C}$, et al. Oncology education for family medicine residents: a national needs assessment survey. BMC Med Educ. 2020;20(1):283.

30. Lee J, Galli J, Siemon J, Huang M, Schlumbrecht M. Assessment of cancer survivorship training and knowledge among resident physicians in obstetrics and gynecology. J Cancer Educ. 2019. https:// doi.org/10.1007/s13187-019-01652-w.

31. Page MJ, McKenzie JE, Bossuyt PM, Boutron I, Hoffmann TC, Mulrow $\mathrm{CD}$, et al. Updating guidance for reporting systematic reviews: development of the PRISMA 2020 statement. J Clin Epidemiol. 2021;134:103-12.

32. Nekhlyudov L, Mollica MA, Jacobsen PB, Mayer DK, Shulman LN, Geiger AM. Developing a quality of cancer survivorship care framework: implications for clinical care, research, and policy. J Natl Cancer Inst. 2019;111(11):1120-30.

33. Shapiro CL, Jacobsen PB, Henderson T, Hurria A, Nekhlyudov L, $\mathrm{Ng}$ A, et al. ReCAP: ASCO core curriculum for cancer survivorship education. J Oncol Pract. 2016;12(2):e145-17.

34. UNESCO: International Standard Classification of Education ISCED. In.; 2012.

35. Barr H, Freeth D, Hammick M, Koppel I, Reeves S: Evaluations of interprofessional education A United Kingdom review for health and social care. 2000.

36. Study Quality Assessment Tools. https://www.nhlbi.nih.gov/ health-topics/study-quality-assessment-tools. Accessed 1 Jan 2021

37. Hong QN, Fàbregues S, Bartlett G, Boardman F, Cargo M, Dagenais P, et al. The mixed methods appraisal tool (MMAT) version 2018 for information professionals and researchers. Educ Inf. 2018;34:285-91.

38. Berrett-Abebe J, Cadet T, Nekhlyudov L, Vitello J, Maramaldi P. Impact of an interprofessional primary care training on fear of cancer recurrence on clinicians' knowledge, self-efficacy, anticipated practice behaviors, and attitudes toward survivorship care. J Cancer Educ. 2019;34(3):505-11.

39. Buriak SE, Potter J. Impact of an online survivorship primer on clinician knowledge and intended practice changes. J Cancer Educ. 2014;29(1):114-21.

40. Chaput G, Hendricks K, D'Souza V, Shulha M. Educating primary care providers regarding cancer survivor issues Workshop results. Can Fam Physician. 2018;64(2):S63.

41. Daly JM, Howald AG, Filchner KA, Miller BJ, Lyons L, Denlinger $\mathrm{CS}$, et al. Enhancing cancer survivorship through improved provider communication, care coordination, and professional education. J Clin Oncol. 2016;34(3):104. https://doi.org/10.1200/jco.2016.34. 3_suppl.104.

42. Donohue S, Haine JE, Li Z, Trowbridge ER, Kamnetz SA, Feldstein DA, et al. The impact of a primary care education program regarding cancer survivorship care plans: results from an engineering, primary care, and oncology collaborative for survivorship health. J Cancer Educ. 2019;34(1):154-60.

43. Fulbright JM, Hein W, Stegenga K, Alsman K, Sharma M, Ryan R, et al. Implementing a stepwise educational approach for bridging the gap between specialty and primary care for childhood cancer survivors. J Cancer Surviv. 2020;14:660-5.

44. Grant M, Economou D, Ferrell B, Uman G. Educating health care professionals to provide institutional changes in cancer survivorship care. J Cancer Educ. 2012;27(2):226-32.

45. Harvey A, Zhang Y, Phillips S, Suarez R, Dekle L, Villalobos A, et al. Initial outcomes of an online continuing education series focused on post-treatment cancer survivorship care. J Cancer Educ. 2020;35(1):144-50. 
46. Jacob RA, Hyatt V. A graduate medical education curriculum to introduce the concept of cancer survivorship. MedEdPORTAL. 2018;14:10673.

47. Meacham LR, Edwards PJ, Cherven BO, Palgon M, Espinoza S, Hassen-Schilling L, et al. Primary care providers as partners in long-term follow-up of pediatric cancer survivors. J Cancer Surviv. 2012;6(3):270-7.

48. Merriam SB, DiNardo D. Talking sex with cancer survivors: effects of an educational workshop for primary care providers. J Gen Intern Med. 2018;33(2):353.

49. Nolan TS, Hatfield R, Browning KK, Kue J, Klemanski DL. Survivorship fellowship: evaluation and evolution of a program for advanced practice providers. Clin J Oncol Nurs. 2019;23(6): 575-8.

50. Perloff T, Dawkins M, Hurd M, Wang J, Hallmeyer S. Planning for survivorship after checkpoint inhibitors: a multidisciplinary education initiative. J Clin Oncol. 2019;37:98.

51. Piper A, Leon L, Kelly H, Bailey A, Wiley G, Lisy K, et al. Clinical placement program in cancer survivorship for primary care providers 2017-2019. J Cancer Surviv. 2020;14(1):14-8.

52. Risendal B, Westfall JM, Zittleman L, Hodgson C, Garrington T, Sutter C, et al. High Plains Research Network Community Advisory C: Impact of cancer survivorship care training on rural primary care practice teams: a mixed methods approach. J Cancer Educ. 2020. https://doi.org/10.1007/s13187-020-01788-0.

53. Rushton M, Morash R, Larocque G, Liska C, Stoica L, DeGrasse C, et al. Wellness Beyond Cancer Program: building an effective survivorship program. Curr Oncol. 2015;22(6):e419-34.

54. Schilling G, Niebling W, Mack-Hennes A, Arnold D. Cancer survivorship in Germany: education of general practitioners-why and how. Oncol Res Treatment. 2016;39:111.

55. Schwartz LF, Braddock CH 3rd, Kao RL, Sim MS, Casillas JN. Creation and evaluation of a cancer survivorship curriculum for pediatric resident physicians. J Cancer Surviv. 2018;12(5):651-8.

56. Smith K, Emery J, Jefford M, Shibaoka M, Barrett M. Upskilling the primary care workforce in cancer survivorship. Asia Pac J Clin Oncol. 2018;14:180.

57. Tan W. Cancer survivorship focused education in Filipino nurses in Florida: assessment of understanding and take home-messages/immediate recall. Support Care Cancer. 2017;25(2):S110.

58. Evans J, Nolte L, Piper A, Simkiss L, Whitfield K, Jefford M. A clinical placement program for primary care professionals at a comprehensive cancer centre. Aust Fam Physician. 2016;45:606-10.

59. Buriak SE, Potter J, Bleckley MK. Using a predictive model of clinician intention to improve continuing health professional education on cancer survivorship. J Contin Educ Heal Prof. 2015;35(1):57-64.
60. Price DW, Miller EK, Rahm AK, Brace NE, Larson RS. Assessment of barriers to changing practice as CME outcomes. J Contin Educ Heal Prof. 2010;30(4):237-45.

61. Kelly D, Tangney B. Adapting to intelligence profile in an adaptive educational system. Interact Comput. 2006;18(3):385-409.

62. Young K, Kim J, Yeung G, Sit C, Tobe S. Physician preferences for accredited online continuing medical education. J Contin Educ Heal Prof. 2011;31:241-6.

63. Grudniewicz A, Kealy R, Rodseth RN, Hamid J, Rudoler D, Straus SE. What is the effectiveness of printed educational materials on primary care physician knowledge, behaviour, and patient outcomes: a systematic review and meta-analyses. Implement Sci. 2015;10(1):164

64. Grimshaw JM, Shirran L, Thomas R, Mowatt G, Fraser C, Bero L, et al. Changing provider behavior: an overview of systematic reviews of interventions. Med Care. 2001;39(8 Suppl 2):II2-II45.

65. Eccles M, Grimshaw J, Walker A, Johnston M, Pitts N. Changing the behavior of healthcare professionals: the use of theory in promoting the uptake of research findings. J Clin Epidemiol. 2005;58: $107-12$.

66. Klufas A, Shin G, Raphael R, Sarfaty SC, Hirsch AE. A thorough analysis of the current state of cancer education in medical schools and application of experimental teaching techniques and their efficacy. Adv Med Educ Pract. 2020;11:931-46.

67. Vaona A, Banzi R, Kwag KH, Rigon G, Cereda D, Pecoraro V, et al. E-learning for health professionals. Cochrane Database Syst Rev. 2018;1(1):CD011736.

68. Johnson CE, Lizama N, Garg N, Ghosh M, Emery J, Saunders C. Australian general practitioners' preferences for managing the care of people diagnosed with cancer. Asia Pac J Clin Oncol. 2014;10(2):e90-8.

69. Zhang Z, Zhan X, Li Y, Hu R, Yan W. Web-based training for primary healthcare workers in rural China: a qualitative exploration of stakeholders' perceptions. PLoS One. 2015;10(5):e0125975.

70. Rabe A, Sy M, Cheing W, Lucero-Prisno D. COVID-19 and health professions education: a $360^{\circ}$ view of the impact of a global health emergency. MedEdPublish. 2020;9(1):148.

71. Kuh GD, Ikenberry SO, Jankowski NA, Cain TR, Ewell PT, Hutchings $\mathrm{P}$, et al. Using evidence of student learning to improve higher education. John Wiley \& Sons, Incorporated: New York; 2015 .

Publisher's note Springer Nature remains neutral with regard to jurisdictional claims in published maps and institutional affiliations. 